doubtedly be more severe than at present, while the northern winter would be to some extent mitigated. Precession would have the effect of causing this state of things to alternate in the two hemispheres. The argument is perfectly simple and definite. and can only be questioned on the score of degree, not of fact. It thus passes from the domain of astronomy to that of meteorology. Here the ground is very debatable, and Mr. Culverwell's discussion of the solar radiation incident on individual zones of the earth may be regarded as a decided contribution to a study of this part of the question. But his researches do not seem to be necessarily so conclusive against the astronomical theory of an Ice Age as this author supposes. For the present purpose, however, enough has been said as to the application of the theory to our own planet.

The conditions which hold in the case of Mars resemble in a remarkable manner those which hold in the case of the earth, except in one particular. The eccentricity is $\cdot 0933$, and hence $b=$ II. The constant $a=\cdot 27$. These values of $a$ and $b$ apparently afford an excellent example of the conditions required by the theory for a glacial epoch in the southern hemisphere of Mars. It would be illogical to compare the state of corresponding regions on the earth and on Mars, because the concomitant circumstances cannot be expected to be the same. But it is reasonable to suppose that in corresponding seasons the latter planet should show different phenomena in the two hemispheres. As an index of these variations we naturally look to the polar caps, the size of which is known to vary greatly with the seasons. The results to be expected are of this kind :

$\begin{array}{clccc}\text { Hemisphere. } & \begin{array}{c}\text { Season. } \\ \text { N }\end{array} & \begin{array}{c}\text { Duration. } \\ \text { Summer }\end{array} & \begin{array}{c}\text { Climate. } \\ \text { Long }\end{array} & \begin{array}{c}\text { Cool } \\ \text { Size of Cap. } \\ \text { Min. }\end{array} \\ \text { N } & \text { Winter } & \text { Short } & \text { Mild } & \text { Lesser Max. } \\ \text { S } & \text { Summer } & \text { Short } & \text { Hot } & \text { Min. } \\ \text { S } & \text { Winter } & \text { Long } & \text { Cold } & \text { Greater Max. }\end{array}$

The amount of heat during summer in either case being the same, there is room for question as to the relative size of the two minima. But it seems clear that the radiation incident on the southern hemisphere will be transformed into heat at a higher temperature than in the northern. According to the laws of thermodynamics it should, therefore, be more effective in the south. The total energy received is the same, but the available energy is greater. Or the matter may be considered differently. It is quite conceivable that during the long cool summer the temperature would not rise above the melting point of ice or whatever substance is in question, while it would be otherwise during the short hot summer. An approach to this condition would lead us to expect the more pronounced minimum in the southern hemisphere.

To compare the suggestions of theory with the facts of observation, we can turn to a recent paper on the subject by Mr. Lowell. ${ }^{1} \mathrm{He}$ concludes that the caps are composed of ice and not carbonic acid, on account of the difficulty of obtaining the latter substance in a liquid form, a state which he considers proved by observation to exist on Mars. He expresses a belief that the Martian sky is cloudless during the day and that the surface of the planet is protected by cloud at night. It must be confessed that the regularity of transition at sunrise and sunset from one condition to the other almost surpasses our belief and tends to discredit the deductions from the study of projections upon the terminator. Mr. Lowell then considers the evidence of the polar caps. The result is to confirm the expectations formed above, and the conclusion is perhaps the more convincing because the writer seems to find the phenomena surprising. And this point is rather important, for the evidence as to the maxima is not so complete as could be desired. It is to

1 "Mars on Glacial Epochs," by Percival Lowell : Proceedings of the American Philosophical Society, Nov, 16,1900 .

$$
\text { NO. I 648, vOL. 64] }
$$

be hoped that Mr. Lowell's examination of this part of the question will lead to the acquisition of more complete and satisfactory evidence.

With regard to the minima, Mr. Lowell does not give the simple explanation suggested above, but attributes the phenomena observed to a deficiency of precipitation. In fact, he professes to prove that "as the precipitation increases a time must come when the southern minimum will actually exceed the northern one in size, and do so more and more, indefinitely." As no physical principle is invoked to account for this result, it would seem to be based on assumption. Examination shows that the assumptions tacitly involved are (I) that the maximum of each cap is increased in the same ratio, (2) that the amount melted at each cap remains exactly the same as before. It would then follow that in each hemisphere the rate of proportionate growth of the minimum would exceed that of the maximum. We now introduce the observed fact that the ratio of maximum to minimum is greater in the southern hemisphere. This, added to the foregoing, is necessary and sufficient to prove that the rate of proportionate growth of the minimum is greater in the southern than in the northern hemisphere. But the observed fact employed might equally well have been stated in this form : comparing the southern with the northern hemisphere, the ratio of the minima does not exceed the ratio of the maxima ; and by assumption (I) the latter is constant. Hence, even on the assumptions the words italicised in the above quotation do not appear justified. The southern minimum may tend towards a relative increase, but there is a limit to the increase. The general idea is perhaps suggestive, but the second assumption involved must be considered highly improbable, and without it the whole theory fails.

At the end of the paper Mr. Lowell turns his attention to the eccentric position of the southern cap. He declines to believe that this well known peculiarity is due to local elevation, but, on the contrary, attributes it to a region of depression, where the cap has acquired an exceptional thickness. The phenomenon is a very curious one, but speculation as to its origin has probably not much value.

\section{THE TELAUTOGRAPH.}

$\mathrm{I}$ an article on " Electric Signalling" which appeared recently in these columns (vol. lxiv, p. 6) we referred to the writing telegraph invented by Mr. Foster Ritchie. We have since had an opportunity of examining the instrument and seeing it at work, and are enabled to give a full description of it. The problem of devising an apparatus which should telegraphically transmit the actual handwriting or drawing of the person sending the message is one which has attracted a number of inventors. The difficulties to be overcome are, however, numerous, and in consequence up to the present no really satisfactory instrument has been invented. These difficulties seem to have been mastered in Mr. Ritchie's telautograph in a very ingenious manner, and the instrument is one which should prove thoroughly trustworthy and serviceable. Although it is not to be expected that the telautograph will replace ordinary telegraphic apparatus to any very marked extent, seeing that the speed of signalling is necessarily limited, yet there are numerous cases in which it should be of use. To give only one example, there are many persons possessing private telephone lines who would gladly supplement them with an instrument of this kind by which written instructions can be sent whether there is any one present to receive them or not. Other cases of like kind will doubtless occur to the reader.

One of the chief merits of the Ritchie telautograph lies. in the fact that only two wires are needed to connect the 
transmitting and receiving instruments ; these are connected as a single loop earthed at each end, thus providing three distinct circuits since currents can be sent through either of the two wires to return by earth or can be sent through one wire to return by the other. The general principles of the apparatus will be understood from Figs. I and 2. Fig. I is from a photograph of the instrument with the cover and paper removed in order to show the working parts. It will be seen from this photograph that the complete apparatus consists both of a transmitting instrument, fixed on the horizontal baseboard, and a receiving instrument, supported on the four upright pillars. Fig. 2 is a diagram of the connections, only the

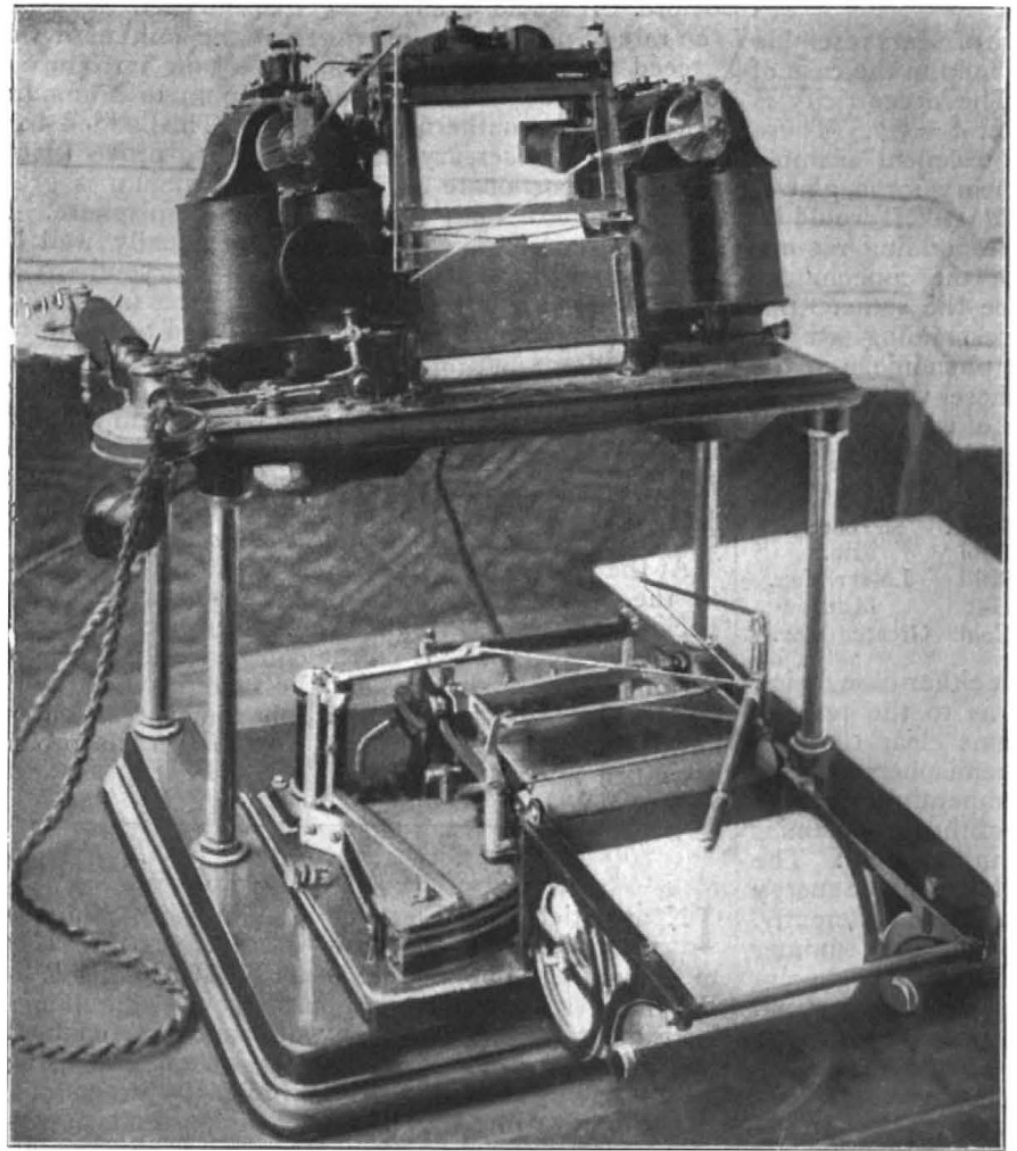

FIG. I.-General view of the Telautograph. nected to two sets of levers, LL, which actuate the sliding contacts of two rheostats, $\mathrm{RR}^{\prime}$; these rheostats are connected one in series with each of the two lines, $R$ in the line $E W W E^{\prime}$, and $R^{\prime}$ in the line $E W^{\prime} W^{\prime} E^{\prime}$. As the resistances of the rheostats are varied by the motion of the sliding contacts corresponding to the motion of the pencil, $\mathrm{A}$, the currents in the two lines will vary. These currents pass through and deflect the moving coils of two galvanometers of the d'Arsonval type, $\mathrm{G}, \mathrm{G}^{\prime}$, in the receiving instrument ; these coils are connected by two sets of levers, $L^{\prime} L^{\prime}$, to the receiving pen, $B$. It will thus be seen that the position of the pen $B$ is controlled by the deflections of the two galvanometers, which are in their turn dependent on the position of the transmitting pencil $\mathrm{A}$ : the pen will therefore exactly follow in its motions the movements of the pencil and will consequently repeat on the paper at the receiving end the drawing made on that at the transmitting end. The currents, after traversing the coils of $\mathrm{G}$ and $\mathrm{G}^{\prime}$, pass through the relays $D$ and $D^{\prime}$ (the use of which will be explained presently) and then return by earth.

From what has been said so far it is obvious that the receiving pen will copy the movements of the pencil $A$, whether the pencil is being used to write on the paper or merely being moved about above it. It is necessary to prevent the pen $B$ from making marks on the paper except when $A$ is actually writing on the paper at the transmitting end. This is effected in the following ingenious manner. A small induction coil at the transmitting end has its primary circuit, $\mathrm{P}$, completed through a contact, $M$, attached to the desk on which the writing paper rests: the terminals of the secondary coil, $\mathrm{S}$, are connected to the line wires, $w, w^{\prime}$, and the circuit is completed at the receiving end through the relay $\mathrm{H}$ and the condenser $\mathrm{K}^{\prime}$. Intermittent currents are thus sent round the circuit SWHW'S and, actuating the relay $\mathrm{H}$, put in action a pen lifting magnet (not shown in the diagram) which raises the bar $F$ and holds the pen $B$ off the paper. When the operator starts writing the pressure on the

principal connections being shown in order to avoid a multiplicity of lines.

When the operator wishes to send a message he takes up the transmitting pencil, A, and with the point shifts to the left the catch $\mathrm{c}$. This operation actuates a grip which shifts the paper forward at both ends of the line, thus bringing up a clean piece to write upon, and also connects up the transmitting and disconnects the receiving apparatus at the home end. At the same time, it reverses the connections of one of the sets of batteries, two sets of which are used, one at each end of the line, which are normally connected in opposition so that when the connections of one set are reversed by shifting the catch $\mathrm{C}$ they are connected in series. The operator now proceeds to write on the transmitting paper : the pencil, A, is conNO. I648, vOL. 64$]$ paper breaks the contact at $M$ and thus stops the vibratory currents ; the relay $\mathrm{H}$ is released and the bar $\mathrm{F}$ falls back, thus allowing the pen to come into contact with the receiving paper. It will be noticed that the vibratory currents are superimposed on the ordinary line currents, but they are prevented from affecting the receiving pen by the selfinduction of the galvanometer circuit, whilst at the same time the line currents are prevented from passing through the relay $H$ by the condensers $K$ and $K^{\prime}$. A small amount of the intermittent current does pass through the galvanometer coils, but this is, as a matter of fact, advantageous, as it prevents, by the slight vibration it produces, any tendency to sticking.

When the writer has filled up the strip of paper he again shifts the clutch $\mathrm{C}$ and this moves forward the 
paper at his end and also, through the operation of the relay $D$, shifts that at the receiving end. At the same time the pen $B$ returns to the ink bath and takes a fresh supply of ink : the ink bath is not shown in Fig. 2, but can be seen, with the pen resting in it, in Fig. I in front of the
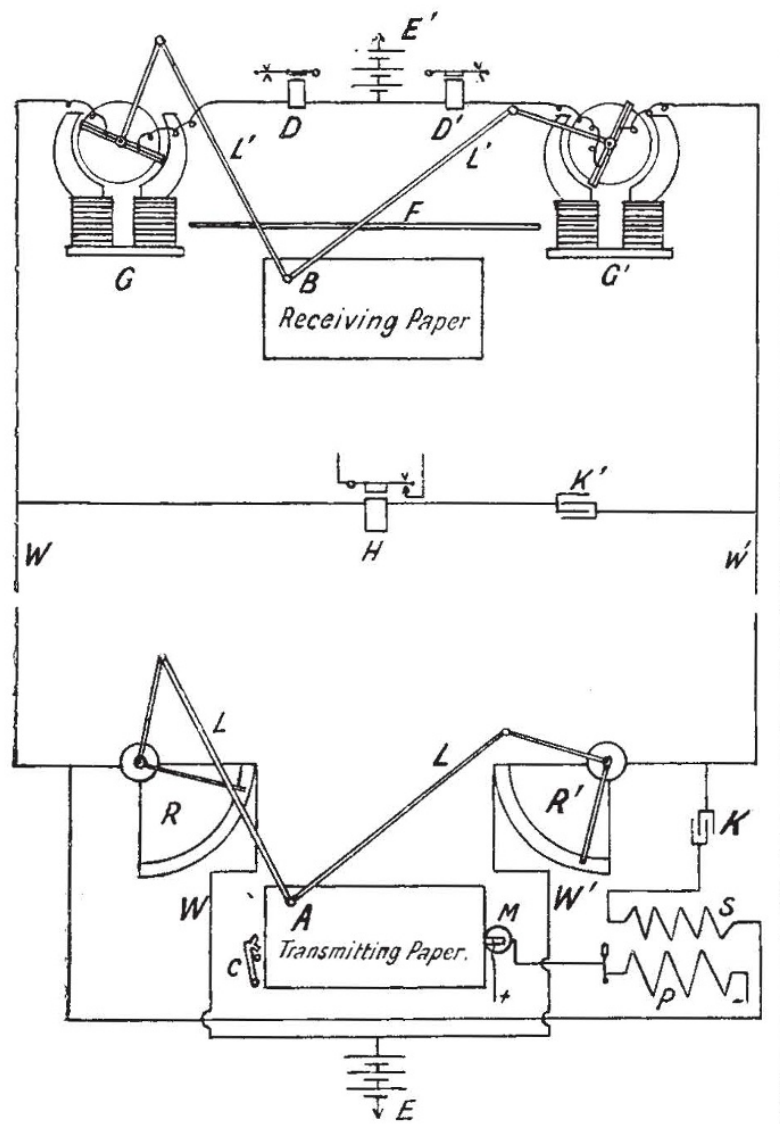

FIG. 2.-Diagram of telautograph connections.

galvanometer on the left. The pen, which is shaped like a small pipe, the bowl being a reservoir for the ink, holds sufficient ink to cover the amount of paper exposed at one time. The relay $\mathrm{D}^{\prime}$ controls a local bell circuit and is used for ringing up. Neither the connections of this bell circuit nor of the paper shifting magnet are shown in Fig. 2 , the relays only being shown in order to avoid unnecessary complication.

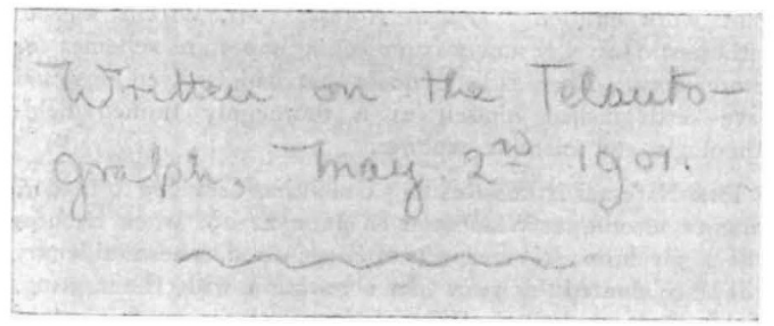

FIG. 3.-Transmitted message.

A specimen of the writing transmitted by the telautograph is shown in Figs. 3 and 4. Fig. 3 shows the words as written in pencil at the transmitting end, and Fig. 4 as received at the far end. These words were transmitted over an artificial line nearly 300 miles long; it will be NO. I 648 , vOL. 64$]$ seen that although the writing is somewhat distorted it does not lose its character and is indeed a very fair reproduction. The words were written on the first telautograph that $\mathrm{Mr}$. Ritchie has constructed; in future instruments it is to be expected that the reproduction will be even more accurate, as several improvements in detail have been introduced, but it must be admitted that the performance of the present apparatus leaves little to be desired. There is no difficulty in writing, in spite of the pencil being attached to the rheostats and having to move

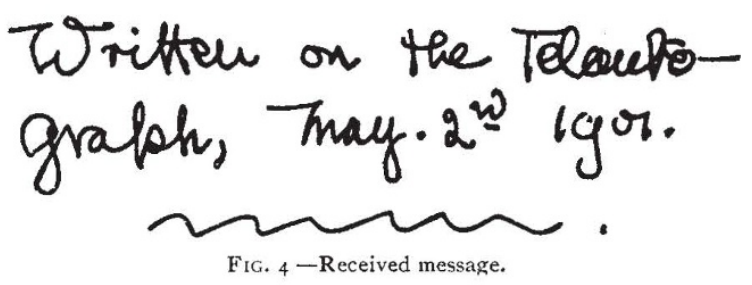

them; everything seems to move very freely and it is almost as easy to write as with an ordinary pen. Moreover, as long as the paper is not shifted, the writer can go back and make alterations and additions with perfect accuracy.

We are much indebted to the Telautograph Co. for allowing us to examine the instrument, and to Mr. Foster Ritchie for very kindly explaining to us the details of its construction.

\section{NOTES}

MR. BALFOUR has often pleaded for the increase of facilities for scientific research, and has pointed out how, in this respect, our country compares unfavourably with some others. The festival dinner of the Medical Graduates' College and Polyclinic, on May 22, gave him another opportunity to remind the public of existing deficiencies and the duties of wealthy citizens towards them. As pureiy scientific research can never be self-supporting, and as, moreover, every addition to knowledge is of value, it has peculiar claims upon the public and the nation. How small, comparatively, is the response to these claims is known to all of us. Here science is tolerated but it cannot be said to be encouraged; and this because the people who have the means to further scientific interests are not in sympathy with them. The State leaves the adequate provision for scientific research to private benevolence, but liberal benefactions are few and far between, so work which would be done here if means were available is left to other nations. Many men of science spend their private incomes to carry on investigations which elsewhere would be afforded generous support, and they often have to leave work unfinished because such assistance is not forthcoming. "I do not believe," said Mr. Balfour, "that any man who looks round the equipment of our universities or medical schools, or other places of education, can honestly say in his heart that we have done enough to equip research with all the costly armoury which research must have in these modern days. We, the richest country in the world, lag behind Germany, France, Switzerland, and Italy. Is it not disgraceful? Are we too poor or are we too stupid? Do we lack the imagination required to show what these apparently remote and abstract studies do for the happiness of mankind? We can appreciate that which obviously and directly ministers to human advancement and facility, but seem, somehow or another, to be deficient in that higher form of imagination, in that longer sight, which sees in studies which have no obvious, necessary or immediate result the foundation of the knowledge which shall give far greater happiness to mankind than any immediate, material, industrial advancement can possibly do; and I fear, and greatly fear, that, lacking that 